\title{
One-to-One Computing, One-to-One Learning: Predictors for Implementation of Differentiated Instruction
}

\author{
Patricia Murthy, Eileen Shannon, Thomas K. Short, \\ Elsa-Sofia Morote, Albert Inserra \\ Dowling College
}

\begin{abstract}
Author Note
Doctoral student Debra Nicosia participated in this paper in fulfillment of a research course.
\end{abstract}

\begin{abstract}
The purpose of this study was to examine the degree to which four variables are predictive of of teachers' propensity to implement differentiated instruction. The variables in question are: collaborative learning; project-based learning implementation; teachers' knowledge regarding the use of technology; and years teaching in a one-to-one high school computing environment. The participants were 170 teachers in one-to-one computing environments who responded to an online survey sent via an email link from the International Society for Technology in Education (ISTE) and the One-to-One Institute. A path analysis was performed to evaluate the strength of each variable in predicting differentiated instruction implementation. Strong relationships were found between the measured variables in the one-to-one computing environment. The four variables included in the model predict $84 \%$ of teachers' implementation of differentiated instruction. The findings suggest that pedagogical best practices such as collaborative learning and project-based learning, coupled with a technology-rich environment, will result in the likeliness of teacher's implementation of differentiated instruction.
\end{abstract}

Keywords: differentiated instruction; one-to-one computing; technology; collaborative learning; project-based learning

As the quantity and complexity of technology in schools increases, teachers need direction and training on how to use technological tools effectively to improve learning. One promising avenue for such improvement is differentiated instruction, which seeks to address diverse learning needs by tailoring activities, materials and other aspects of the instructional environment (Bearne, 1996; Tomlinson, 1999; as cited in Tomlinson, et al., 2003, p. 121).

Classrooms are filled with a broad range of learners who require instruction according to their learning styles, and it is challenging for teachers to differentiate the curriculum to meet all learning needs. While instruction must be delivered to students in mixed ability classrooms, teachers must also meet $21^{\text {st }}$ Century Skills expectations for all students 
(U.S. Department of Education, 2010).

There are clear advantages when technology is tailored to address individual learning needs. Sams and Bergman (2013) contend that working one-to-one with each student engages individual thinking and integrates differentiated instruction. "Education is for everyone, but the way in which we deliver education-and the way in which students receive it-is not the same for everyone" (p. 20). According to Fullan, integrations between technology and pedagogy "can be designed to create learning experiences that operate to produce high, natural yield in what is learned" (2013, p. 17).

This study seeks to determine the best predictors of a teacher's propensity to implement differentiated instruction in a one-to-one computing environment. For the purpose of this study, a one-to-one computing environment exists when every teacher and student has access to a laptop, Internet service, printers, and computer software within a school system, and may use it anytime and any where. Four variables were examined as possible predictors of the implementation of differentiated instruction: collaborative learning; project-based learning implementation;knowledgeregardingtheuse oftechnology; andyearsofexperience.

\section{Literature Review}

It was nearly a century ago that John Dewey called for schools to give students real life work experiences in order to develop deep, imaginative learning (Dewey, 1909). This practical approach still has great currency. Technology is pervasive in modern life, and the current learning environment requires an instructional program that includes technology. One-to-one school environments, including teachers' with technology knowledge, offer students project-based and collaborative learning experiences.

\section{Differentiated Instruction}

Differentiated instruction on the most basic level means tailoring instruction to meet the individual learning needs of students, whether it be in the area of content, process, environment or products. According to Carol Ann Tomlinson, an educator and advocate of differentiating instruction to best meet student needs; it is the effort a teacher makes to "address student variance" among learners in a classroom (Tomlinson, 2003, p. 124).

Differentiated instruction should be based on student interests while meeting the current goal of college and career readiness (Tomlinson et al., 2003). Committing to a framework in the teaching structure is a critical element in effectively implementing differentiated instruction, as noted by Heacox (2009). Since students learn in diverse ways, it is more important to accurately identify the needs of students than just having a pre-set intervention menu from which to choose. Clarke (2012) describes a differentiation program called Pathways used in a Vermont middle/high school that individualizes the curriculum with the interests of the learners coming first. This type of program "puts the student at the center of the learning process" and couples it with "relevant work for the $21^{\text {st }}$ century" (p. 61). Assessments of the program in the two years it is being delivered shows that even the most recalcitrant student can show improvement and earn high 
school credits.

Sams and Bergmann (2013) reexamine the way educators teach and utilize class time with students through a technology-based approach called flipped learning. The flipped learning approach to lesson delivery gives students the opportunity to view lectures at home via video as homework. Instead of taking time to lecture during class, educators can use class time to work one-on-one with students on higher-order thinking and differentiate the instruction. Students meet the same learning objectives through projectbased learning in a flipped classroom environment as students in the traditional classroom environment.

\section{Collaborative Learning}

Saavedra and Opfer (2012) contend that online technologies are well-suited to support collaborative learning, and conclude that it is crucial for teachers to learn to maximize the pedagogical value of these technologies. The examination of nine lessons using the science of learning concluded that it is necessary to explicitly teach technology skills, despite the challenge in assessing retention of the skills. Collaborative learning experiences offer students opportunities to apply such skills. Collaborative learning is considered a necessary condition for optimal learning in the $21^{\text {st }}$ century. Rosen and Beck-Hill (2012) examined the effects of one-to-one computing programs on teaching and learning practices, and student learning. Four hundred seventy six students in grades four and five and their teachers from four elementary schools participated in the study. They found one-to-one computer programs helped differentiate teaching and learning practices, and increased Math and Reading achievement. It also showed to have positive effects on student attendance and discipline. One-to-one computing environments are important contributors to academic success of diverse learners.

\section{One-to-One Computing Environments}

Livingston (2008) discusses the impact, expense, and knowledge required to meet the demands of one-to-one computing environments. She notes that teacher training is necessary in order to maximize the benefits of one-to-one technology integration. The availability of technology itself-as well as the occurrence of technical issues and the availability of technology support-all impact the incorporation of differentiated instruction in the curriculum. Nolan, Preston and Finkelstein (2012) argue that, for students to be actively engaged, learning experiences must be highly relevant. For this reason, technology is essential to reaching students; however, the implementation of technology must be driven by pedagogy rather than mere novelty.

\section{Project-Based Learning}

Levin and Schrum (2012) studied eight schools that were technology-rich and also had track records of successful technology integration into the instructional program. They found that project-based learning activities were a creative use of technology for students. "The goal was to educate students for work and for life in the $21^{\text {st }}$ Century, not just to add 
technology" (p. 51). Project-based learning was an explicit part of the curriculum design in all eight schools.

Dobbertin (2012) offers an example of well-implemented project-based learning using differentiated instruction in a charter school math classroom. In this case, the teacher was able to differentiate learning for all students with project-based learning targets. Richardson (2012) notes that personalized learning experiences are necessary for students in today's classrooms, and that this is likely possible with technology playing a major role.

\section{Teacher Knowledge of Technology}

The level of a teacher's knowledge of technology is also an important factor when it comes to effective instructional practices. Effective technology training for teachers was discussed by Sommervold and Goodwin (2012) and the fact that teachers are still refusing to use computers, whether it is in a one-to-one computing environment or other, less saturated technology environments. They examined a cohort of 40 teachers who were offered professional development through a grant fund. Teachers created two lessons. After the first lesson, a formative assessment was used to measure student understanding. If students understood, the instructor proceeded to lesson two; if students did not understand, the instructor altered the lesson and taught again. This program helped instructors to focus on what was directly needed in the classroom.

Norris and Soloway (2004) discuss the impact technology is having on our classrooms and the fact that technology saturates every aspect of our daily lives. They examined students engaging in a multitude of collaborative efforts using handheld devices with networked PCs, probeware, and digital cameras. One of many benefits of technology is that when it comes to collaboration, sharing is simple, and those students using technology to collaborate can receive instant feedback from peers and teachers. The benefit of collaboration and use of technology together are not always recognized by teachers if they do not feel comfortable implementing the technology.

\section{Design}

This study examines the validity of four variables as predictors of whether teachers will implement differentiated instruction in a one-to-one computing environment. These variables are: collaborative learning; project-based learning implementation; knowledge regarding the use of technology; and years of experience.

Collaborative learning. Collaborative learning means using technology that promotes learning, including communicating information among groups of students and teachers in the one-to-one computing environment.

Project-based learning. Project-based learning occurs in the one-to-one computing environment when students use computer programs, media creation tools, and other computer-based tools that support students in the representation of their ideas. 
Teacher knowledge of technology. Knowledge regarding the use of technology is the capacity to apply technological skills in a one-to-one computing environment.

Differentiated instruction. Differentiated instruction occurs when teachers assign individual students a choice of multiple computer-based resources to communicate their learning in a one-to-one computing environment (Short, 2011, p.7-10).

Years of experience. Years in a one-to-one computing environment were organized by groups: novice (0-3 years), experienced (4-7 years), and veteran (8 years and over).

\section{Survey Instrument}

The survey instrument was part of a large study conducted by Short (2012) who administered it through a web based program in which 170 teachers were chosen for the purposeful sample from 209 total teacher participants. The participants were high school Math, Science, Social Studies, English and Foreign Language teachers who received an email containing a link to the survey from the International Society for Technology in Education (ISTE) and the One-To-One Institute. Consent was given when the participant clicked the link to the survey in the email. The survey was juried by a five-member committee of instructional technology practitioners who did not eliminate any items. In addition, construct validity was determined through various factor analytic procedures.

The setting was based on one-to-one computing school districts. The data collected was gleaned from a three part, 56 item survey. Part one of the survey contained general demographic information in which years in the one-to-one computing environment was included and the level of implementation utilized a Likert scale (Almost Never, Seldom, Sometimes, Frequently, Almost Always). The survey items were grouped according to dimension, range of scores, and origin for each dimension. Data was validated by factor analysis. Reliability of the variables was above $90 \%$.

\section{Results}

According to the Path Analysis as seen in Figure 1, strong correlations were seen between collaborative learning and project-based learning implementation $(r=.86)$, collaborative learning and knowledge regarding the use of technology $(r=.56)$; projectbased learning implementation and knowledge regarding the use of technology $(r=.55)$. Weak correlations are shown between years of experience and the rest of the variables.

In predicting differentiated instruction, we found that the combination of four variables, project-based learning implementation $(\beta=.45)$, collaborative learning $(\beta=.42)$, knowledge regarding the use of technology $(\beta=.12)$ and years of experience $(\beta=.06)$ in the one-toone computing environment, all show a positive influence to differentiated instruction implementation. Years of experience in the one-to-one computing environment was the least influential variable in predicting the implementation of differentiated instruction, though it remains an indicator. The major predictors, collaborative learning and projectbased learning implementation were both highly correlated as well as the highest predictors 
of implementation of differentiated instruction. The combination of collaborative learning, project-based learning implementation, knowledge regarding the use of technology, and years of experience in the one-to-one computing environment, accounts for $84 \%$ of the variance of teachers' implementation of differentiated instruction.

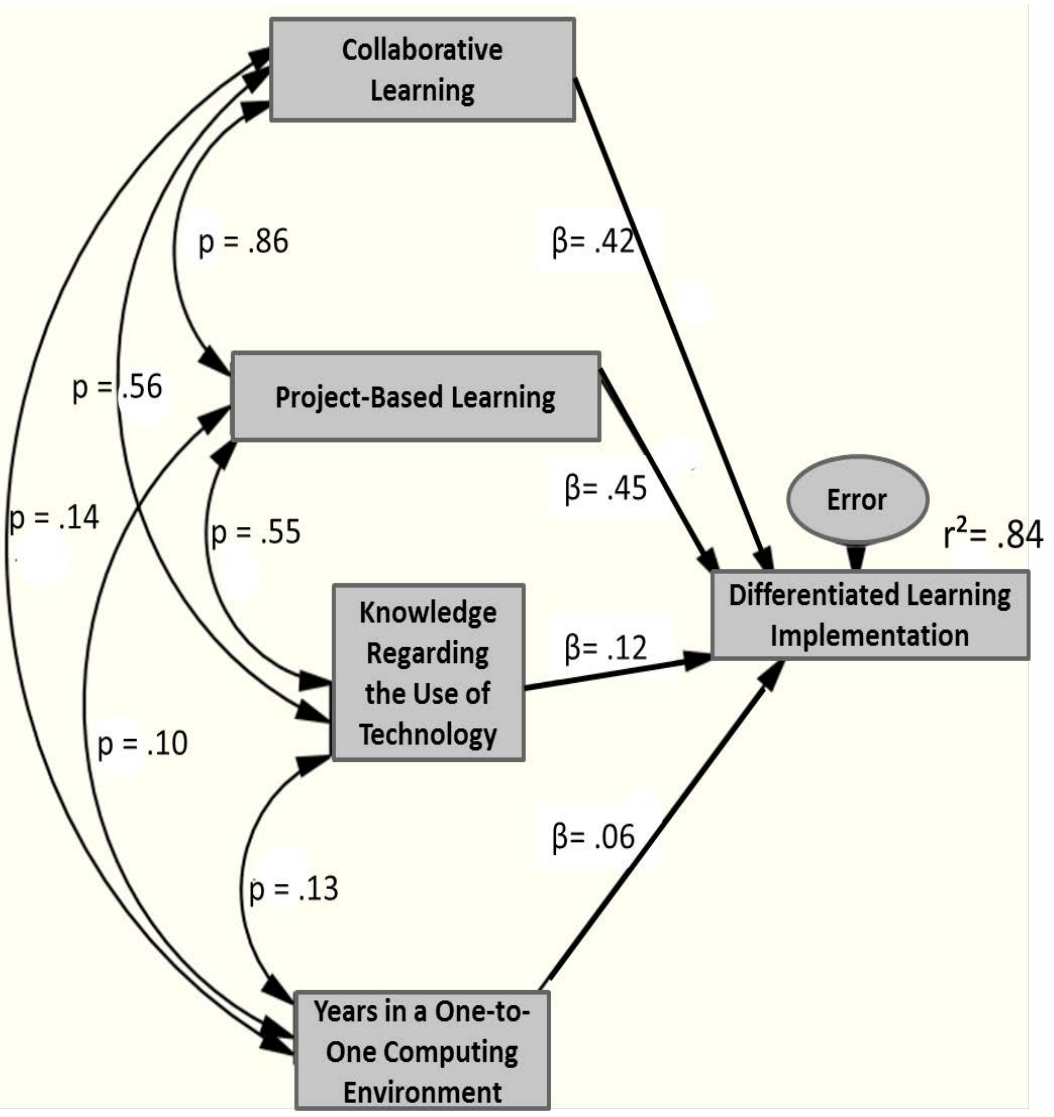

Figure 1 - Path Analysis of differentiated instruction Implementation Variables: Collaborative Learning, Project-Learning Implementation, Knowledge Regarding the use of Technology, Years in One-to-One Computing Environment and Differentiated Instruction Implementation.

\section{Conclusion}

This study predicts the best model for implementation of differentiated instruction in a one-to-one computing high school learning environment. It analyzes the strength of the relationship between collaborative learning, project-based learning implementation, and knowledge regarding the use of technology and years of experience in the one-toone environment. The results indicated that all variables were significant predictors of differentiated instruction implementation.

The foundation and principles at the core of education in the $21^{\text {st }}$ Century are impacted by technology changes at such a rapid rate, that it is challenging to examine any given innovation in a single moment in time. Technology is better preparing students to compete in a highly technical global economy. Parallel to technology transformation is learning theory and educational pedagogy. The implications of this study reflect the need for an 
educational shift in which pedagogy and technology must merge to become symbiotic. Technology will no longer be viewed or implemented as an add-on or enhancer of learning but rather will become an inseparable element in learning.

Goodwin (2011) recognized good news and bad news of the one-to-one environment: the good news was high student engagement, improved technology skills and over-all costefficiency, but the bad news was the mixed or no change results on student achievement. Goodwin describes such results as "anemic" and a cause for educators to take pause (p. 79). Ultimately, however, he found that one-to-one initiative will only be as effective as the institutions that adopt and implement it. It is teacher training in delivering curriculum in technology rich environments incorporating best practices will result in differentiating the program to meet individual needs.

A conclusion may be drawn from these findings to support current theories in best teaching practices in one-to-one computing environments. It can be said that teachers who employ instructional practices such as collaborative learning, project-based learning implementation, and have knowledge of technology are likely to implement differentiated instruction in the one-to-one computing environment. There is a strong relationship between the pedagogical approaches of collaborative learning and projectbased learning implementation, both of which deepen student learning experiences and address the diverse needs of all learners.

Teachers using technology every day (ex: Facebook, texting) still may not understand the best pedagogical teaching practices while incorporating technological applications in the classroom. There is a sense that there is no time to learn so many new technologies (Sommervold \& Goodwin, 2012). Also, among the many challenges in utilizing technology is pedagogy, classroom management, technology management, school purchasing, and teacher/student location needs are included as highly important (Norris \& Soloway, 2004). The benefits to teaching are equal in importance indicating that teachers need knowledge of how to incorporate technology effectively.

\section{Implications and Future Studies}

In physics, fusion is complete when two elements form into one; resulting in a release of energy. When high levels of technology are fused with best practices in pedagogy as examined in this study, the result will be an exponential release of learning. Time and money should be devoted to reinforcing the fusion of instructional delivery approaches such as collaborative learning, project-based learning implementation and differentiated instruction with technology for teachers.

Since this study was limited to the one-to-one computing environment it would be a worthy endeavor to conduct similar research in environments with higher ratios of people (teachers and students) to technology devices. Also, further study may be done in one-to-one Middle and Elementary level schools, to examine differences or similarities according to school level. 


\section{References}

Clarke, J. H. (2012). Invested inquiry. Educational Leadership, 69(5), 60-64.

Dewey, J. (1909). Moral principles in education. Retrieved 12 12, 2012, from The Project Gutenberg: http://www.gutenberg.org/files/25172/25172-h/25172-h.htm

Dobbertin, C. B. (2012). “Just How I need to Learn It". Educational Leadership, 69(5), 66-70.

Fullan, M. (2013). Stratosphere integrating technology, pedagogy, and change knowledge. Toronto, Ontario: Pearson Canada Inc.

Goodwin, B. (2011, February). Research Says.../One-to-One Laptop Programs Are No Silver Bullet. Educational Leadership, 68(5), 78-79.

Heacox, D. (2009). Making differentiation a habit: How to ensure success in academically diverse classrooms.

Levin, B. B., \& Schrum, L. (2012, March). Technology-Rich Schools UP CLOSE. Educational Leadership, 70(6), 51-55.

Livingston, P. (2008). 1-to-1 Learning . Education Week, 18-21.

Nolan, J., Preston, M., \& Finkelstein, J. (2012, October). Can you DIG/IT. Phi Delata Kappan, 42-46.

Norris, C., \& Soloway, E. (2004). Envisioning the Handheld-Centric Classroom. Journal of Educational Computing Research, 30(4), 281-294.

Richardson, W. (2012). Preparing Students to Learn without Us. Educational Leadership, 69(5), 22-26.

Rosen, Y., \& Beck-Hill, D. (2012). Intertwining digital content and a one-to-one laptop environment in teaching and learning: lessons from the tme to know program. Journal of Research on Technology Education, 44(3), 225-241.

Saavedra, A. R., \& Opfer, D. (2012, October). Learning 21st-century skills requires 21 stcentury teaching. Phi Delta Kappan, 5-13.

Sams, A., \& Bergmann, J. (2013, March). Flip Your Students' Learning. Educational Leadership, 70(6), 16-20.

Short, T. K. (2011). High school teacher knowledge and implementation of individualized and differentiated instruction in a one-to-one computing environment. Dowling College ProQuest Dissertations and Theses. 
Sommervold, C., \& Goodwin, M. (2012). Never Too Late to Learn. Learning and Leading with Technology, 39(7), 20-22.

Tomlinson, C., Brighton, C., \& Hertberg, H. (2003). Differentiated instruction in response to student readiness, interest and learning profile in academically diverse classrooms: A review of literature. Journal for Education for the Gifted, 27(2/3), 119-145.

U.S. Department of Education. (2010). Evaluation of Evidence-Based Practices in OnLine Learning A Meta-Analysis and Review of Online Learning Studies. 